\title{
The midline craniofacial skeleton in holoprosencephalic fetuses
}

\author{
Inger Kjær, Jean W Keeling, Niels Græm
}

\begin{abstract}
Craniofacial skeletal development in eight human holoprosencephalic fetuses from second trimester abortions were examined by radiography and histology. The whole spectrum of associated facial malformations from anophthalmia through cyclopia, ethmocephaly, cebocephaly, and median cleft lip to short philtrum was represented. Cases with the most severe facial malformations also had the most severely affected facial skeleton. In the facial skeleton, the premaxilla was most often affected; it was absent in seven cases and malformed in the one with only a short philtrum. This and other facial skeletal malformations can be explained as abnormal fusion of the facial bones because of defective development of the nasal cartilage. The occipital bones were normal, but the basicranial skeleton anterior to the spheno-occipital junction was affected in all cases. The findings support the hypothesis that the facial malformations in holoprosencephaly result from disturbance in embryonal life of the mesoderm at the rostral end of the notochord.
\end{abstract}

The holoprosencephaly spectrum encompasses a group of phenotypically related conditions with defective midline cleavage of the embryonal forebrain and associated facial malformation. Its aetiology is heterogeneous. Most cases are related to genetic disorders, for example, trisomy 13 and 18 , the $18 p$

Institute of Orthodontics, Royal Dental College, Nørre Alle 20, DK-2200 Copenhagen N, Denmark. I Kjær

Maternity Department, John Radclifie Hospital, Oxford.

J W Keeling

Pathological-Anatomical Institute, Herlev Hospital, Copenhagen, Denmark.

N Græm

Correspondence to Dr Kjær

Received for publication 5 March 1991.

Accepted for publication 3 April 1991. and 18q monosomy syndromes, and Meckel's syndrome. ${ }^{1-5}$

Morphological studies of holoprosencephaly have emphasised the median facial anomalies. ${ }^{25-7}$ They can be grouped in order of decreasing severity as follows. In anophthalmia, the most extreme variant, there is neither nose nor proboscis and the mandible is underdeveloped. In cyclopia, a single median eye is associated with arhinia and a proboscis. In ethmocephaly, two close set eyes are associated with arhinia and there is usually a proboscis. In cebocephaly, there is ocular hypotelorism associated with a single nostril nose. Cases with median cleft lip have hypotelorism, flat nose, and absence of the intermaxillary segment of the face. In the less severe variants only minor facial anomalies, such as a short upper lip or a single central incisor, are seen.

The spectrum of brain malformations encountered is alobar, semilobar, and lobar holoprosencephaly. ${ }^{7}$ In all three types there is absence of the olfactory tracts. In alobar holoprosencephaly the cerebral hemispheres are fused and enclose a single prosencephalic ventricle representing the lateral and third ventricles. In the other and less severe forms, there is partial fusion of the hemispheres and partial subdivision of the ventricular cavity.

The prenatal development of the skeleton between the holoprosencephalic brain and the abnormal face has been studied in only a few cases. It has been examined in histological sections in two term fetuses with cyclopia, ${ }^{8}$ in an 8 week fetus also with cyclopia, ${ }^{9}$ and in four second trimester fetuses with varying severity of facial malformation. ${ }^{10}$ Not surprisingly, the cranial skeleton was malformed. However, our knowledge of the skeletal malformations in the whole spectrum of this syndrome is still poor. Increased insight into how the skeleton is affected may help to explain the supposed interaction between the developing brain, skeleton, and face. This is important not only in diagnosing and describing holoprosencephalic cases, but also in understanding these relationships in both normal and other pathological cranial development. The purpose of the present study, in which both radiography and histology were used systematically, was to map the malformations of the midline cranial skeleton three dimensionally in a series of fetuses with holoprosencephaly of varying severity. 


\section{Material and methods}

The series comprised eight human holoprosencephalic fetuses from legally approved therapeutic abortions. At necropsy special attention was paid to skeletal radiographic analysis, organ dissection, chromosomal analysis, and facial features. The main data are shown in the table and the faces are shown in fig 1 . The whole spectrum of facial malformations from anophthalmia to median short philtrum is represented. Most cases had alobar holoprosencephaly. Two of the cases with less severe facial malformation had semilobar holoprosencephaly. The gestational age was determined from the clinical history and from ultrasound scans during the pregnancy. It agreed with the foot length and with the general skeletal maturation assessed by the number of ossified bones of the feet, which, unlike the hands, were not malformed. ${ }^{11}{ }^{12}$ Seven of the eight fetuses had other associated malformations and five had abnormal chromosomes. After necropsy the fetuses were fixed in neutral buffered formalin and after fixation the eight crania underwent radiographic and histological examination.

\section{RADIOGRAPHY OF THE CRANIUM}

The study was confined to the medial parts of the basal and facial cranium situated in the tissue mass, which in the following is named the midsagittal segment.
After the removal of the cranial vault and the mandible, the cranial base was radiographed in vertical projection. After that a tissue block was formed of the central cranial base by letting two sagittal incisions touch the lateral borders of the foramen magnum. The interjacent midsagittal segment was examined in lateral projection. Finally, the midsagittal tissue segments from cases 2 to 8 were divided by two frontal sections into three parts of equal fronto-occipital dimensions: anterior $(\mathrm{Fa})$, middle $(\mathrm{Fm})$, and posterior $(\mathrm{Fp})$. These blocks were examined in frontal projection (fig 2).

A Grenz ray radiographic apparatus, Hewlett Packard, Faxitron Series, $43805 \mathrm{~N}, \boldsymbol{x}$ ray system was used with Kodak X-Omat MA film. The tissue was placed directly on the film envelope. Depending on the size of the specimen the tube voltage varied between 20 and $60 \mathrm{kV}$, and the exposure time from 10 to 60 seconds at 2.8 to $3.0 \mathrm{~mA}$.

\section{ANALYSIS OF THE RADIOGRAPHS}

From the radiographs, enlarged paper copies and drawings of ossified tissue were made and used for detailed analysis. Similar radiographs and outline drawings from a series of normal fetuses with corresponding gestational age, foot length, and general skeletal maturity were used as controls; an example is given in fig 3. General skeletal maturity was assessed by counting the number of ossified bones in

Clinical data, necropsy and chromosomal findings in eight holoprosencephalic fetuses by decreasing severity of facial malformation

\begin{tabular}{|c|c|c|c|c|}
\hline & $\begin{array}{l}\text { Gestational } \\
\text { age }\end{array}$ & Brain & Other findings & Chromosomes \\
\hline $\begin{array}{l}\text { Case } 1 \\
\text { Anophthalmia }\end{array}$ & $14 w$ & Alobar holoprosencephaly & Omphalocele & $46, \mathrm{XX}$ \\
\hline $\begin{array}{l}\text { Case } 2 \\
\text { Cyclopia with proboscis }\end{array}$ & $18 w$ & Alobar holoprosencephaly & $\begin{array}{l}\text { Incomplete rotation of gut. } \\
\text { Meckel's diverticulum }\end{array}$ & Not done \\
\hline $\begin{array}{l}\text { Case } 3 \\
\text { Ethmocephaly } \\
\text { with proboscis }\end{array}$ & $18 w$ & Not specified & $\begin{array}{l}\text { Left sided diaphragmatic } \\
\text { hernia }\end{array}$ & $\begin{array}{l}\text { Unbalanced } 7 ; 20 \\
\text { translocation }\end{array}$ \\
\hline $\begin{array}{l}\text { Case } 4 \\
\text { Ethmocephaly }\end{array}$ & $17 w$ & Alobar holoprosencephaly & $\begin{array}{l}\text { Many dysmorphic features. } \\
\text { No visceral abnormality }\end{array}$ & Trisomy 13 \\
\hline $\begin{array}{l}\text { Case } 5 \\
\text { Cebocephaly }\end{array}$ & $18 w$ & Alobar holoprosencephaly & $\begin{array}{l}\text { Many external and internal } \\
\text { abnormalities }\end{array}$ & Trisomy 13 \\
\hline $\begin{array}{l}\text { Case } 6 \\
\text { Median cleft lip }\end{array}$ & $17 w$ & Semilobar holoprosencephaly & $\begin{array}{l}\text { Many external and internal } \\
\text { abnormalities }\end{array}$ & Probable trisomy 13 \\
\hline $\begin{array}{l}\text { Case } 7 \\
\quad \text { Median cleft lip }\end{array}$ & $20 w$ & Alobar holoprosencephaly & None & Not done \\
\hline $\begin{array}{l}\text { Case } 8 \\
\text { Short philtrum }\end{array}$ & $22 w$ & Semilobar holoprosencephaly & $\begin{array}{l}\text { External dysmorphic } \\
\text { features. No internal } \\
\text { abnormality }\end{array}$ & $\begin{array}{l}46, \mathrm{XY} / 47, \mathrm{XY},+ \text { idic } \\
\text { (15)(pter-?q11:?q11-pter) } \\
\text { de novo }\end{array}$ \\
\hline
\end{tabular}



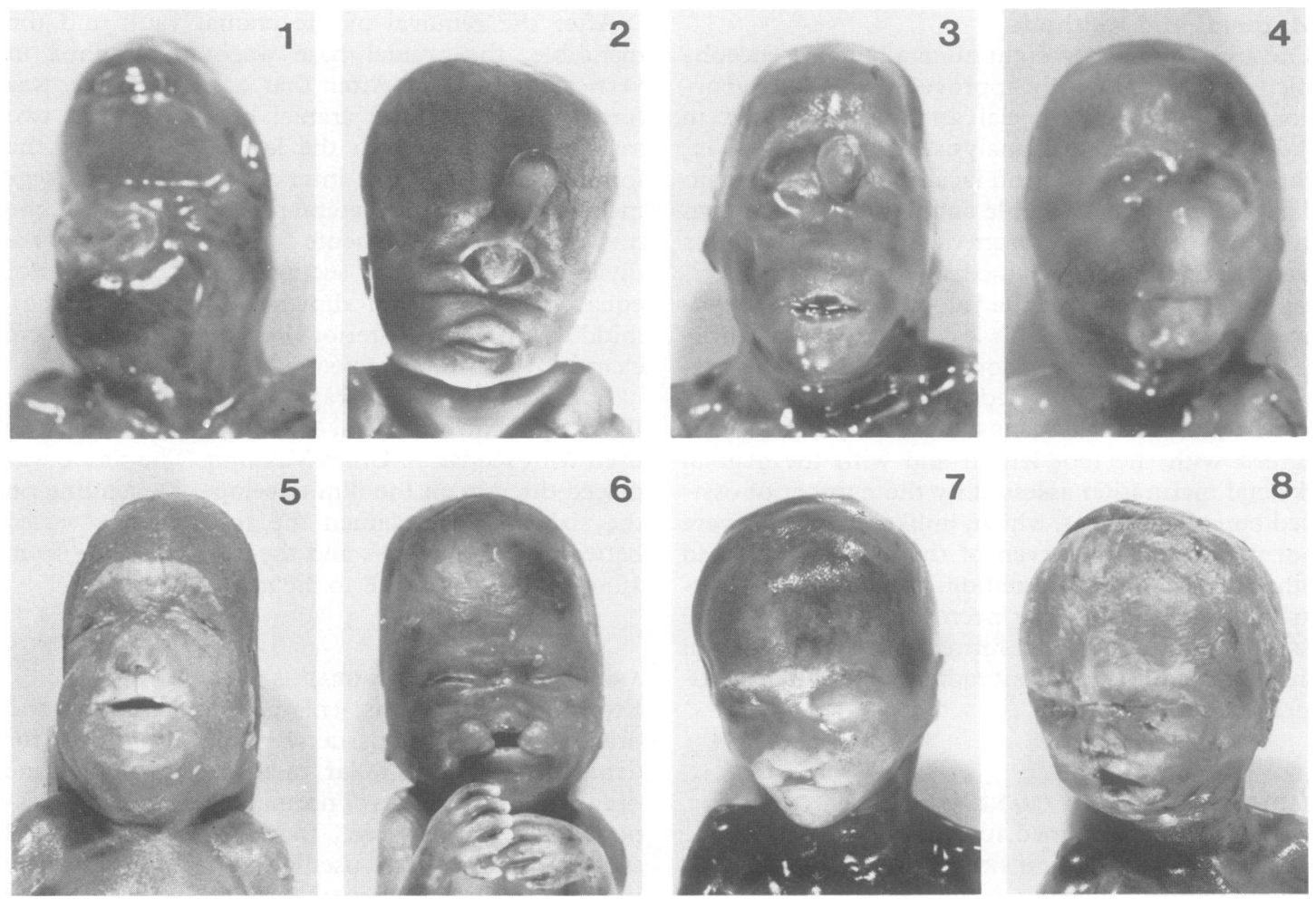

Figure 1 Faces of eight holoprosencephalic fetuses arranged in decreasing severity of facial malformation. Case 1 : anophthalmia. Apart from a central mouth-like opening no facial features are recognisable. Case 2: cyclopia with proboscis. There is synophthalmia and absence of nose. Case 3: ethmocephaly with proboscis. There is severe hypotelorism and absence of nose. Case 4: ethmocephaly. There is severe hypotelorism. Nasal contours are seen, but nostrils are absent. Case 5: cebocephaly. There is moderate hypotelorism and a nose with a single median nostril. Cases 6 and 7: median cleft lip. There is slight hypotelorism. The nose is flat. There are two nostrils. The philtrum area of the upper lip is absent. Case 8: short philtrum. The only apparent facial abnormality is the short upper lip.

the foot. Two normal developmental stages (A and B) covered the material under study (fig 4).

The bones analysed in the midsagittal segment were bones in the cranial base and bones from the facial skeleton. They were the corpus of the occipital bone, postsphenoid bone, presphenoid bone, frontal bone, nasal bone, maxilla, palatine bone, vomer, and premaxilla.

\section{HISTOLOGY}

After radiography, the $\mathrm{Fa}, \mathrm{Fm}$, and Fp tissue blocks were embedded in paraffin and cut frontally in $5 \mu \mathrm{m}$ sections, which were stained with toluidine blue at pH 7. Tissue from a series of normal fetuses with corresponding gestational age was used as a control.

\section{Results}

RADIOGRAPHY

The severity of brain defects, basicranial defects, facial skeletal defects, and facial defects showed good correlation. Even in the case with the least affected face, pathological ossification of facial as well as basicranial bones was seen.

The ossification patterns in the craniofacial bones of the eight holoprosencephalic fetuses are shown in figs 5 and 6 and summarised in fig 7. The abnormalities were symmetrical. The first three columns in fig 7 indicate the findings in the bones of the cranial base. In case 1 the presphenoid bone is not pathologically absent, because it is not normally ossified at the particular stage of development. The columns in fig 7 are arranged by increasing abnormality of the bones. In all cases the corpus of the occipital bone was normal. The presphenoid bone was malformed in all cases, and only in case 8 was the postsphenoid bone normal. Pathological absence of the bones of the cranial base was not seen in any case.

There was a wide range of malformations in the cranial base. In case 8 the presphenoid bone had only a slightly irregular outline. In case 7 there was 


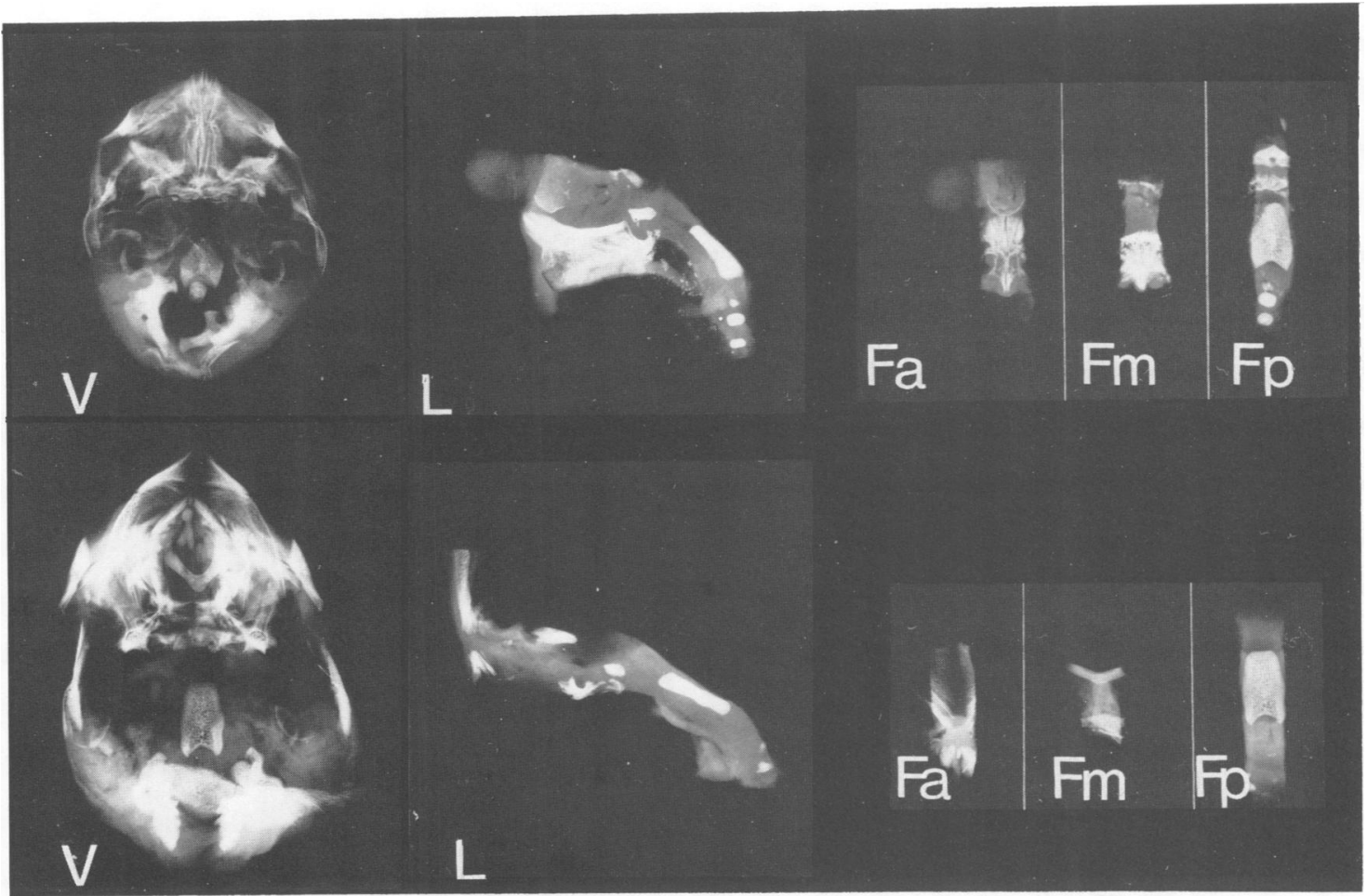

Figure 2 Two examples of cranial radiographs of holoprosencephalic fetuses. Upper row. Case 3: ethmocephaly with proboscis. Lower row. Case 6: median cleft lip. V=vertical projection. L=lateral projection. $F a, F m$, and $F p=$ frontal projections of anterior, middle, and posterior parts of the midsagittal tissue segment, respectively. Comparison of the two cases shows different cranial shape and ossification pattern. In case 3 the nasal bones and the maxillas have coalesced in the midline.

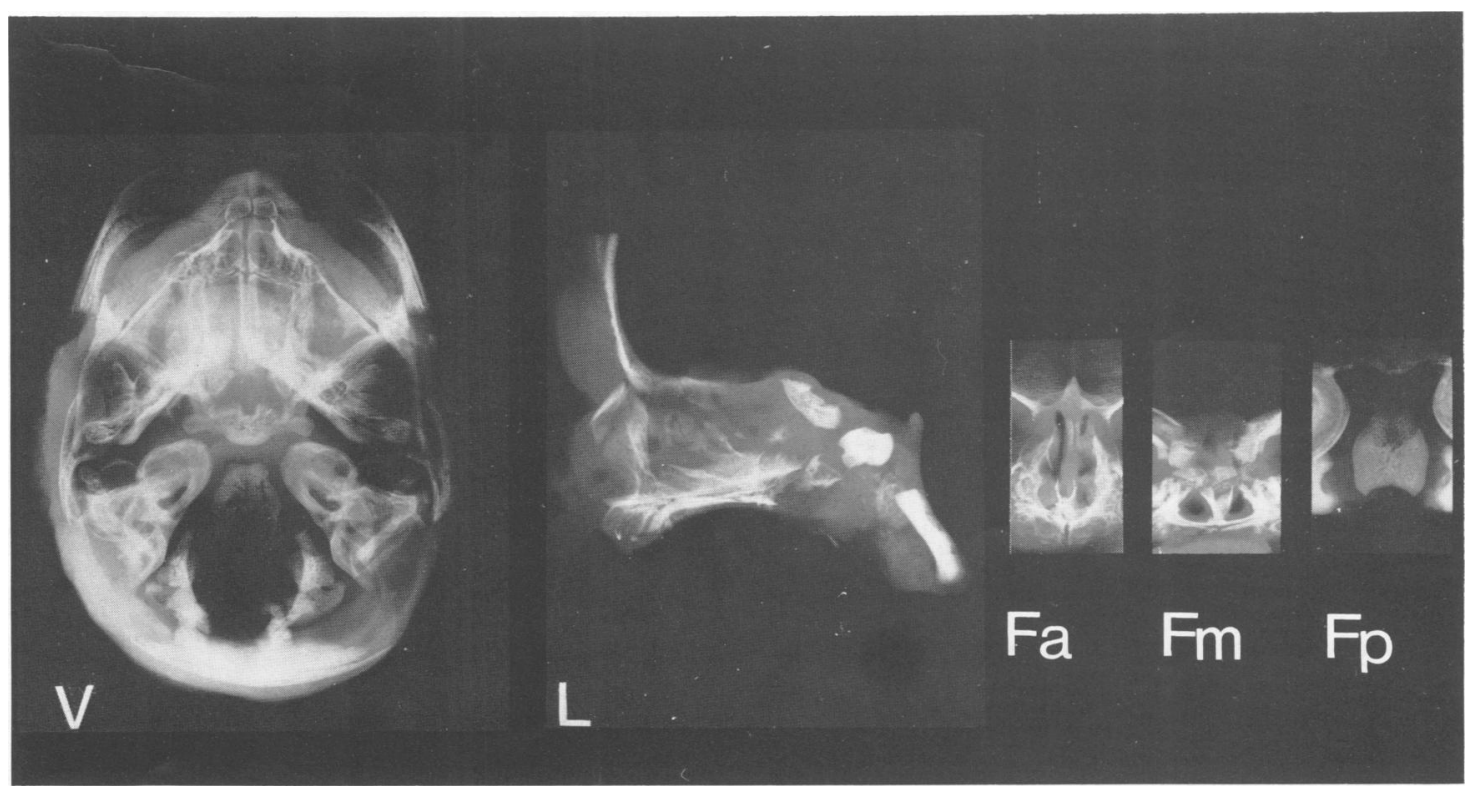

Figure 3 Cranial radiographs of a normal human fetus of 19 weeks' gestation. $V=$ vertical projection. L=lateral projection. $F a, F m$, and $F p=$ frontal projections of anterior, middle, and posterior parts of the midsagittal segment respectively. The position of the bone components is shown in fig 4, lower row. 

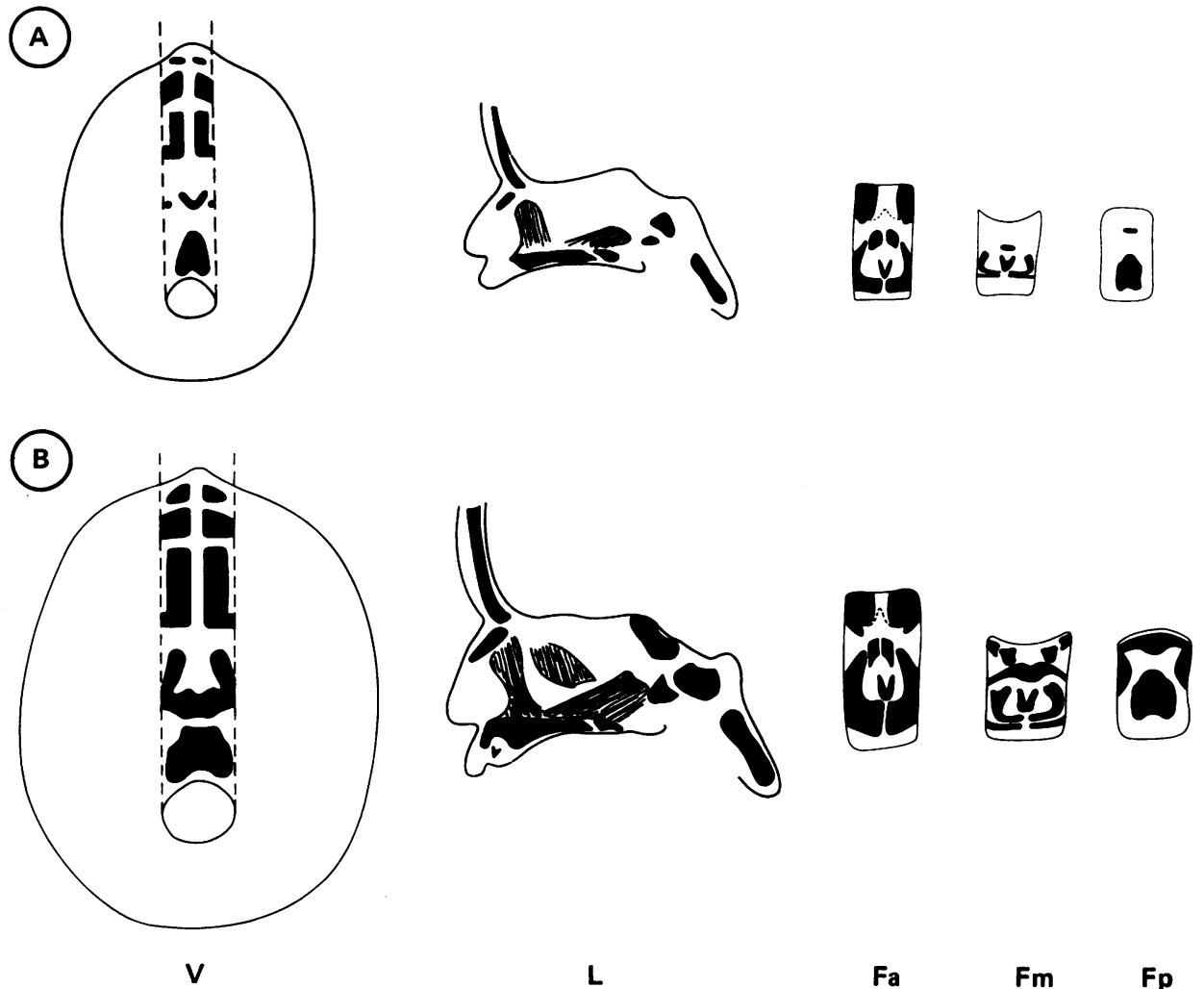

$\mathbf{L}$

Fa

Fm

$F p$

Figure 4 Drawings of radiographs of the midline craniofacial bones in two normal fetuses at different stages of skeletal development. Stage $A$ corresponds to 14 to 16 weeks of gestation and stage $B$ to 16 to 23 weeks. V=vertical projection. $L=$ lateral projection. $F a, F m$, and $F p=$ frontal projections of anterior, middle, and posterior parts of the midsagittal tissue segment, respectively.

synostosis between the two sphenoid components. In the other cases with more severe facial abnormality, the sphenoid components showed more pronounced variation in shape, size, and location (figs 5 and 6).

In fig 7 the last six columns summarise the findings in the facial skeleton. The frontal bone showed least abnormality. It was recognisable in all eight cases, but in the three cases with most severe facial abnormality (including a proboscis) an interfrontal synostosis was seen. Nasal bones could not be identified in case 1 and were rudimentary in case 2 . In case 3 an internasal synostosis was seen and in cases 4 and 5 there was coalescence between the nasal bone and the maxilla bilaterally. In the remaining three cases the nasal bones were normal.

In case 1 maxillary structures could not be identified. There was one irregular bony mass located in the sphenoid and facial area. Cases 2 to 5 had intermaxillary synostosis and in case 6 the maxilla was malformed because of a wide median cleft palate.

In cases 1 to 5 palatal bones could not be recognised. In case 6 the horizontal part of the palatal bone was lacking and the vertical part was abnormally shaped. The vomer could not be recognised in cases 1 to 6 and in case 7 it was severely malformed.

The premaxilla was the most often affected of the facial bones. It was absent in cases 1 to 7 and malformed in case 8 , in which an interpremaxillary synostosis was seen cranially.

\section{HISTOLOGY}

Microscopy of the Fa, Fm, and Fp tissue blocks confirmed the results of the radiographic examination as regards the osseous structures. The cartilage findings were as follows. In case 1 no cartilage was seen and in cases 2 and 3 small islands of cartilage were seen in the proboscides. Ethmoid cartilage was 

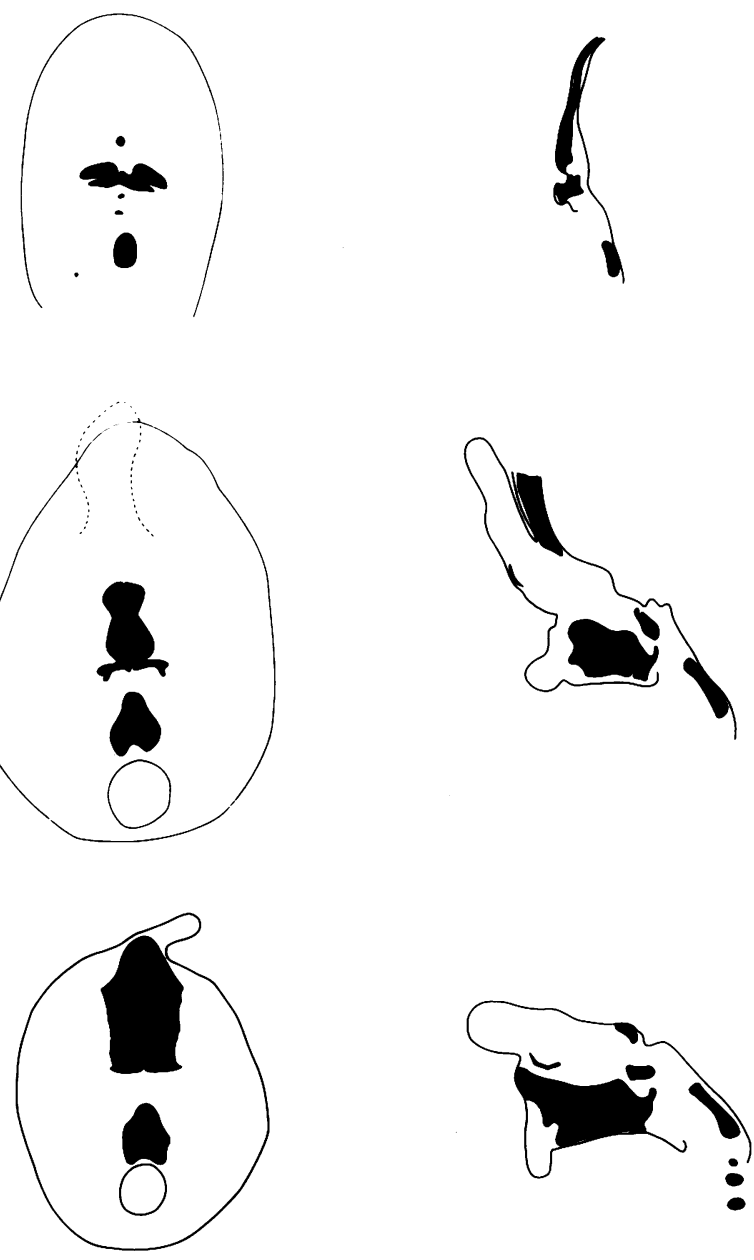

2
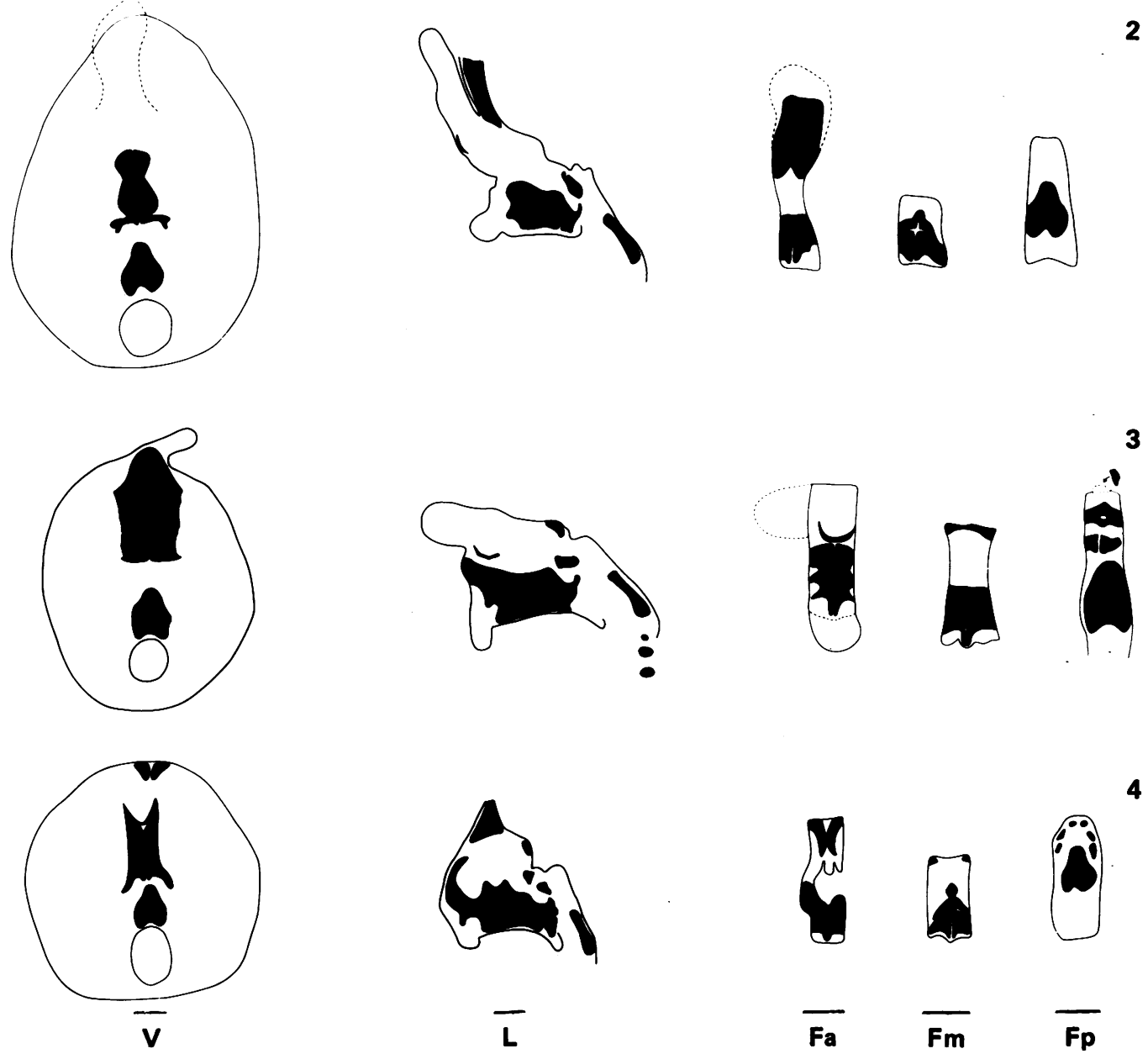

Figure 5 Drawings of radiographs of the midline craniofacial bones. Case 1: anophthalmia. Case 2: cyclopia with proboscis. Case 3: ethmocephaly with proboscis. Case 4: ethmocephaly. V=vertical projection. $L=$ lateral projection. Fa, $F m$, and $F_{p}=$ frontal projections of anterior, middle, and posterior parts of the midsagittal tissue segment, respectively. In case 1 frontal projection was not possible because of a very small anteroposterior diameter. For comparison with normal development case 1 should be compared with stage $A$ and cases 2,3 , and 4 with stage $B$ in fig 4. 

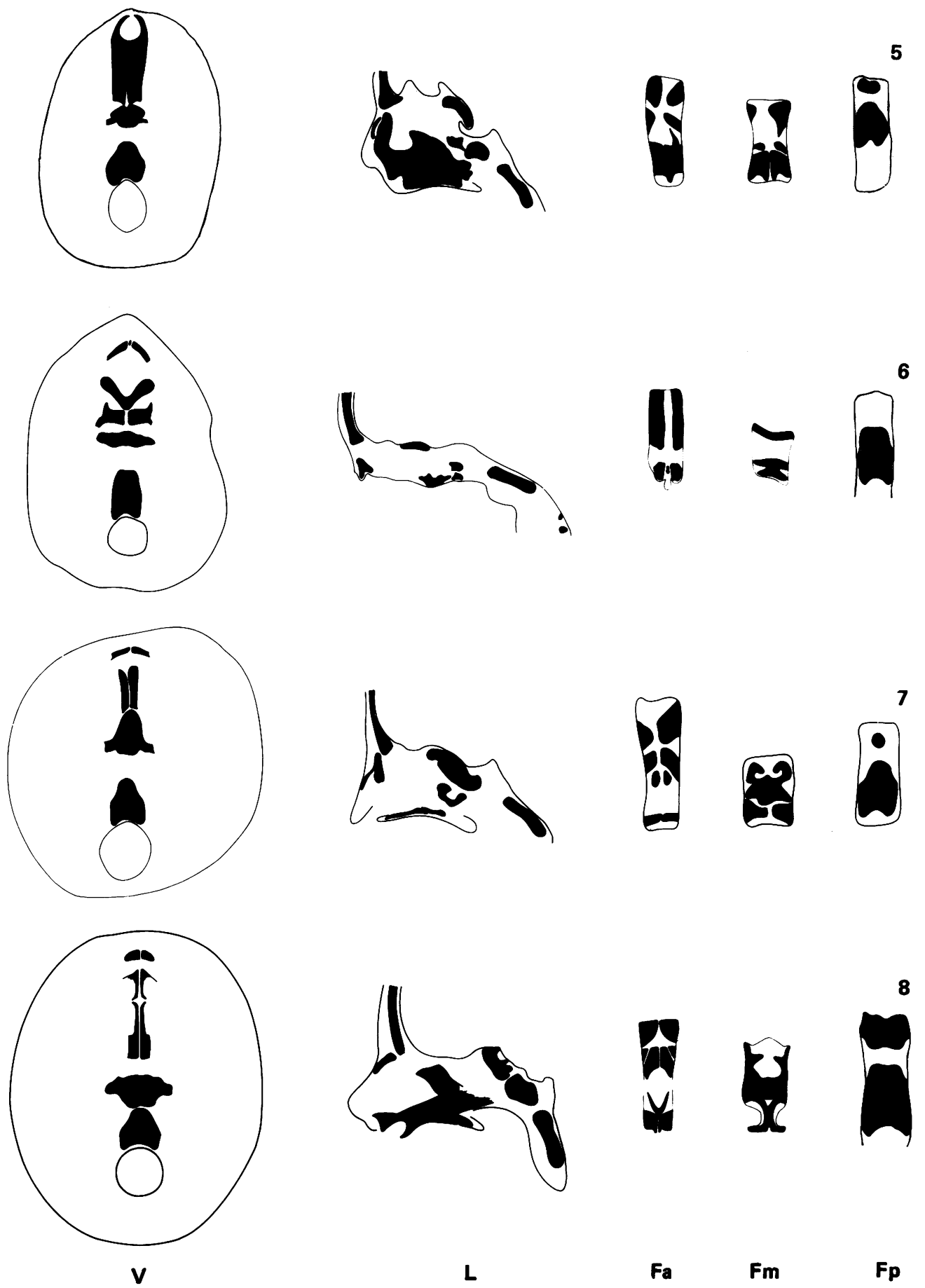

$\mathbf{L}$

Fa

$\mathbf{F m}$

$\mathbf{F p}$

Figure 6 Drawings of radiographs of the midline craniofacial bones in cases 5 to 8. Case 5: cebocephaly. Cases 6 and 7: median cleft lip. Case 8: short philtrum. $V=$ vertical projection. $L=$ lateral projection. $F a, F m$, and $F p=$ frontal projections of anterior, middle, and posterior parts of the midsagittal tissue segment, respectively. For comparison with normal development all cases should be compared with stage B in fig 4. 


\begin{tabular}{|c|c|c|c|c|c|c|c|c|c|}
\hline & & sicranial b & ones & & & Faciz & ones & & \\
\hline & Occipital & $\begin{array}{c}\text { Postsphen } \\
\text { - oid }\end{array}$ & Presphenoid & Frontal & Nasal. & Maxilla & Palatine & Vomer & Premaxilla \\
\hline $\begin{array}{l}\text { Case } 1 \\
\text { Anophthalmia }\end{array}$ & 0 & O & & O & 0 & 0 & 0 & 0 & 0 \\
\hline $\begin{array}{l}\text { Case 2 } \\
\text { Cyclopia } \\
\text { with proboscis }\end{array}$ & 0 & 0 & 0 & O & O & 0 & 0 & 0 & 0 \\
\hline $\begin{array}{l}\text { Case } 3 \\
\text { Ethmocephaly } \\
\text { with proboscis }\end{array}$ & 0 & O & ○ & 0 & O & 0 & 0 & 0 & 0 \\
\hline $\begin{array}{l}\text { Case } 4 \\
\text { Ethmocephaly }\end{array}$ & O & ○ & O & 0 & O & 0 & 0 & 0 & 0 \\
\hline $\begin{array}{l}\text { Case } 5 \\
\text { Cebocephaly }\end{array}$ & O & 0 & 0 & 0 & 0 & 0 & 0 & 0 & 0 \\
\hline $\begin{array}{l}\text { Case } 6 \\
\text { Median cleft lip }\end{array}$ & 0 & ○ & O & O & 0 & 0 & O & 0 & 0 \\
\hline $\begin{array}{l}\text { Case } 7 \\
\text { Median cleft lip }\end{array}$ & 0 & O & O & 0 & 0 & 0 & 0 & O & $\bullet$ \\
\hline $\begin{array}{l}\text { Case } 8 \\
\text { Short philtrum }\end{array}$ & 0 & 0 & O & 0 & 0 & 0 & 0 & 0 & O \\
\hline
\end{tabular}

Figure 7 Schematic presentation of radiographic findings in midline craniofacial bones in eight holoprosencephalic fetuses arranged by decreasing severity of facial malformation. Empty space indicates that the bone was not ossified and is not normally ossified at the particular stage of development. The term malformed covers abnormal shape, location, and coalescence/synostosis.

not seen in case 2 , but in case 3 small, irregular, solid islands close to the midline appeared in the floor of the anterior cranial fossa. In case 4 a malformed multilocular ethmoid cartilage without the normal midline septum was seen (fig $8 \mathrm{~A}$ ). In case 5 one unilocular nasal cavity with an irregular outline was surrounded by ethmoid cartilage (fig 8B). In cases 6 and 7 the nasal cavity was also unilocular, but an incomplete nasal septum was seen (fig $8 \mathrm{C}$ ). In case 8 the shape of the ethmoid cartilage showed only minor deviations from the normal, which is shown in fig $8 \mathrm{D}$.

\section{Discussion}

In attempting to put the pattern of abnormalities in the midline craniofacial skeleton of the holoprosencephalic fetus into a comprehensible framework, it is useful to look at the facial skeleton and the basicranial skeleton separately. As could be expected, this study showed that cases with the most severe facial malformation also had the most severely affected facial skeleton. Case 8 had only slight facial malformation and malformation of the premaxilla only whereas the more severely affected cases had more bones affected. In the cranial base the combined sphenoid bones were malformed in all eight cases, whereas the occipital bones were normal. The spheno-occipital junction thus seems to be the border between abnormal and normal basicranial development in holoprosencephaly. This has not been described before and supports the pathogenic theory of Sperber et al, ${ }^{9}$ who suggested that a crucial point in the development of facial malformations in holoprosencephaly is a disturbance of the mesoderm at the rostral end of the notochord just anterior to what later becomes the occipital bone. Presumably, normal development of the sphenoid bones and the nasal capsule, later becoming the ethmoid bone, depends on the integrity of this prechordal mesoderm. The histological analysis of cases 1 to 8 showed decreasing severity of abnormality also of the cartilaginous nasal capsule, which in normal fetuses fills in the gap between the cranial base and the facial skeleton. This, and the other skeletal findings, leads to a hypothesis that the facial abnormalities in holoprosencephaly are secondary to the abnormalities in the basal cranium. All of the facial skeletal malformations can freely be explained as abnormal osseous fusion resulting from defective development of the nasal cartilage, which normally keeps the neighbouring skeletal elements apart.

Our results are in full accordance with the findings of Sperber et al ${ }^{9}$ who, in a detailed histological study of a $\mathbf{4 0 ~ m m}$ human fetus with holoprosencephaly and cyclopia, showed absence of the nasal capsule and presence of separate maxillary and vomeral bones. Not surprisingly, in our study of a later developmental stage of cyclopia, these bones had partially fused. In another histological study, 


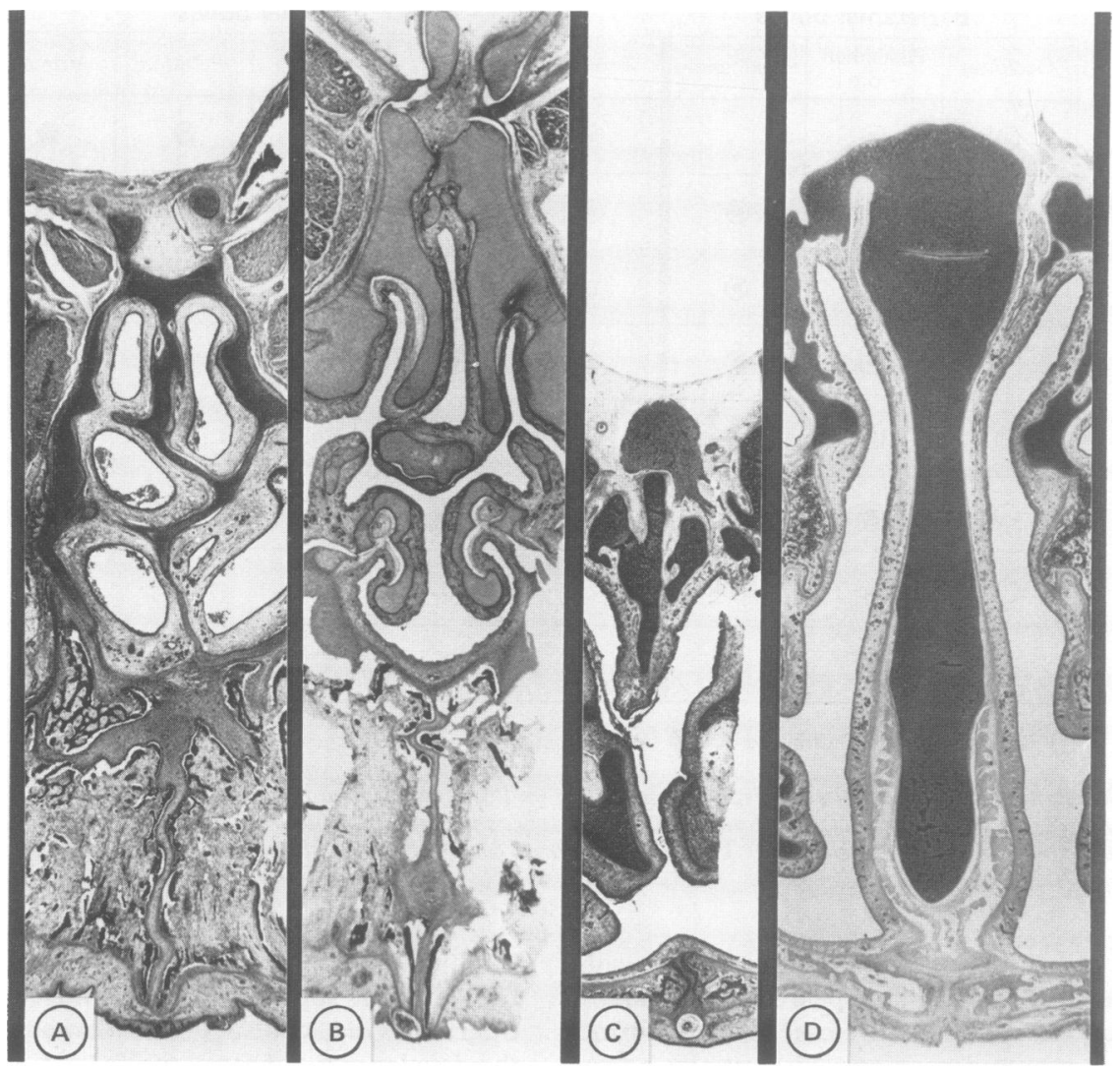

Figure 8 Frontal paraffin sections of tissue block $F$ a from case $4(A)$, case $5(B)$, and case $7(C)$ and from a normal human fetus (21 w gestational age) (D). (Toluidine blue.) ( $A$ ) Malformed multilocular ethmoid cartilage without the normal midline nasal septum. (B) Unilocular nasal cavity surrounded by ethmoid cartilage. (C) Incomplete nasal septum. (D) Normal ethmoid cartilage with a midline septum dividing the nasal cavity.

Sperber et al ${ }^{10}$ examined four human holoprosencephalic fetuses including one with cyclopia from the 14th to 23rd weeks of gestation and showed abnormal facial skeletal development broadly corresponding to our findings. In three of their cases with less severe facial malformation the skull base was apparently normal. In the present investigation in which radiography was also used, the cranial base was affected in all eight cases, but this discrepancy may be because of the different methods of examination.

In this radiographic study covering the whole spectrum of facial malformations in holoprosencephaly, the premaxilla and the presphenoid bone were most often affected. Interestingly, these bones are also those which normally ossify latest among the affected bones. ${ }^{13-15}$ Whether this correlation between normal osseous maturation and frequency of involvement of the craniofacial bones reflects differences in the time of onset or primary location of the defect can only be hypothesised.
The facial defects can partially be understood by considering normal embryological development (fig $9)^{16}$ and most easily seen by considering in turn the abnormalities from case 8 to case 1 . In case 8 with a short philtrum the structures arising from the lowermost portion of the medial nasal swelling were missing. In the more severely malformed cases 7 and 6 with median cleft lip, a greater portion of structures from this swelling were lacking. This combined with the osseous findings in this study, suggests that the premaxilla arises from the top of the median nasal swelling. In case 5 with cebocephaly, all structures from the medial nasal swelling were lacking and the structures from the lateral nasal swellings had fused in the midline and surrounded a central nostril. The involvement of the palatine bone and the vomer in cases 7,6 , and 5 is probably secondary to the medial displacement of the maxilla. In cases 4,3 , and 2 with ethmocephaly and cyclopia, structures from both the lateral and the medial nasal swellings were lacking. In these cases the maxillas 

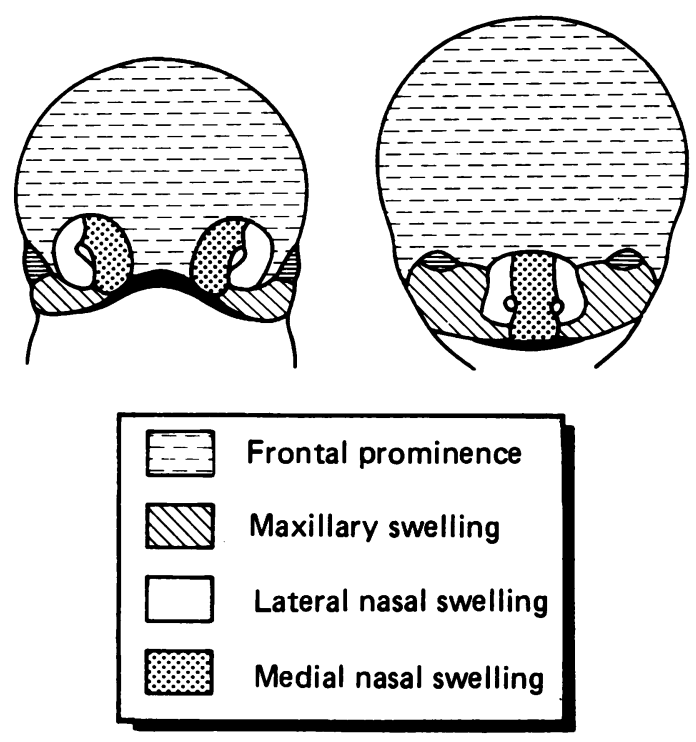

Figure 9 Schematic depiction of facial formation, indicating frontal prominence, maxillary swelling, lateral nasal swelling, and medial nasal swelling in human faces at 6 and 10 weeks of age.

were still present but had fused probably owing to the absence of normal midline structures.

The present material has not allowed a detailed study of the brain. Therefore, an analysis of the correlation between the defects in the brain and craniofacial morphology has not been performed. Presumably, a study of the possible interaction between the development of these structures should be performed on embryos and not on second trimester fetuses.

The investigation was supported by grants $12-7371$, 12-8871, and 12-9662 from the Danish Medical Research Council and by grants from Marie and Knud Øster-Jørgensen's foundations and from the Danish Dental Association (FUT foundation).

1 Bligh AS, Laurence KM. The radiological appearances in arhinencephaly. Clin Radiol 1967;18:383-91.

2 Cohen MM, Jirásek JE, Guzman RT, Gorlin RJ, Peterson MQ. Holoprosencephaly and facial dysmorphia: nosology, etiology and pathogenesis. Birth Defects 1971;7:125-35.

3 Fitz CR. Holoprosencephaly and related entities. Neuroradio$\log y 1983 ; 25: 225-38$.

4 Laurence KM, Ishmael J. Arhinencephaly and 13-15 (D) trisomy. In: Darlington CD, Lewis KR, eds. Chromosomes today. Vol 2. Edinburgh: Oliver \& Boyd, 1969:86-9.

5 Leech RW, Shuman RM. Holoprosencephaly and related midline cerebral anomalies: a review. $\mathcal{f}$ Child Neurol 1986;1:3-18.

6 Dallaire L, Fraser FC, Wiglesworth FW. Familial holoprosencephaly. Birth Defects 1971;7:136-42.

7 DeMyer W, Zemann W, Palmer CG. The face predicts the brain: diagnostic significance of median facial anomalies for holoprosencephaly (arhinencephaly). Pediatrics 1964; 34:256-63.

8 Latham RA. Mechanism of maxillary growth in the human cyclops. F Dent Res 1971;50:929-33.

9 Sperber GH, Johnson ES, Honoré L, Machin GA. Holoprosencephalic synophthalmia (cyclopia) in an 8 weeks fetus. $f$ Craniofac Genet Dev Biol 1987;7:7-18.

10 Sperber GH, Honoré LH, Machin GA. Microscopic study of holoprosencephalic facial abnormalities in trisomy 13 fetuses. Am $\mathcal{f}$ Med Genet 1989;32:443-51.

11 Streeter GL. Weight, sitting height, headsize, foot length and menstrual age of the human embryo. Contrib Embryol Carnegie Inst 1920;11:143-70.

12 Kjaer I. Skeletal maturation of the human fetus assessed radiographically on the basis of ossification sequences in the hand and foot. Am $\mathcal{F}$ Phys Anthropol 1974;40:257-76.

13 Kjaer I. Prenatal skeletal maturation of the human maxilla. $f$ Craniofac Genet Dev Biol 1989;9:257-64.

14 Kjaer I. Ossification of the human fetal basicranium. I Craniofac Genet Dev Biol 1990;10:29-38.

15 Kjaer I. Radiographic determination of prenatal basicranial ossification. F Craniofac Genet Dev Biol 1990;10:113-23.

16 Langman J. Medical embryology. 4th ed. Baltimore: Williams \& Wilkins, 1981. 